\title{
Distribution and determinants of personal exposure to nitrogen dioxide in school children
}

\author{
Catherine H Linaker, Anoop J Chauhan, Hazel Inskip, Anthony J Frew, Alan Sillence, \\ David Coggon, Stephen T Holgate
}

\begin{abstract}
Objectives-To assess the distribution of personal exposures to nitrogen dioxide $\left(\mathrm{NO}_{2}\right)$ in school children, and to investigate factors that might influence personal exposure.
\end{abstract}

Methods- $\mathrm{NO}_{2}$ exposures were assessed by use of passive diffusion tubes for 46 children aged 9-11 years, selected from two Southampton schools. The tubes were worn for seven days, and parallel measurements were made with static samplers in the child's kitchen, living room, classroom, and playground. Information about potential exposures was collected by questionnaire.

Results-Personal exposures to $\mathrm{NO}_{2}$, averaged over seven days, ranged from 11 to $257 \mu \mathrm{g} / \mathrm{m}^{3}$ (6 to $137 \mathrm{ppb}$ ) with a geometric mean of $36 \mu \mathrm{g} / \mathrm{m}^{3}$ (19 ppb). Exposures correlated with concentrations of $\mathrm{NO}_{2}$ recorded in the home, but the relation was far from exact. Factors associated with increased personal exposure included the use of gas appliances in the home, living with one or more smokers, and travel to school by means other than a car. However, together these variables only explained a small part of the variation in personal exposures.

Conclusions-These findings reinforce the need for personal monitoring of exposure in studies investigating potential health effects of $\mathrm{NO}_{2}$ in children.

(Occup Environ Med 1996;53:200-203)

Keywords: nitrogen dioxide; asthma; personal monitoring

Nitrogen dioxide $\left(\mathrm{NO}_{2}\right)$ is a major air pollutant, both indoors and outdoors. It is formed in combustion processes, either directly or through secondary oxidation of nitric oxide (NO). The main outdoor sources in the United Kingdom are motor vehicles and power stations, and indoor sources are principally natural gas for cooking and heating.

Epidemiological studies have linked domestic exposure to $\mathrm{NO}_{2}$ with higher rates of respiratory illness in children, ${ }^{23}$ although the findings have not been entirely consistent. ${ }^{45}$ An increased risk of respiratory disease might occur through an effect on the immune response to infections. ${ }^{6}$ Also, recent experiments have indicated that $\mathrm{NO}_{2}$ may potentiate the response of asthmatic patients to inhaled allergens. ${ }^{78}$

A weakness of many of the published epidemiological studies is their reliance on indirect indices of domestic exposure to $\mathrm{NO}_{2}$ such as the use of gas for cooking. Even where $\mathrm{NO}_{2}$ has been measured in homes, the concentrations may not reliably reflect personal exposures. There is a need for further epidemiological research with direct measures of personal exposure to $\mathrm{NO}_{2}$, concentrating particularly on potentially vulnerable groups such as asthmatic children. As a prelude to such a study, we have carried out a survey to assess the distribution of personal exposures to $\mathrm{NO}_{2}$ in a sample of school children, and to investigate factors which might influence personal exposure.

\section{Method}

The study was carried out at two schools in different neighbourhoods of Southampton, previously found to have contrasting concentrations of $\mathrm{NO}_{2}$ in outdoor air. ${ }^{9}$ Both schools used gas fired central heating. With permission from the teaching staff, letters were sent to the parents of two classes of 9-11 year old children inviting them to participate in the survey. Those who agreed were asked to complete a self administered questionnaire asking about potential exposures to $\mathrm{NO}_{2}$ including the presence of gas appliances in the home, the number of smokers in the household, and how the child travelled to and from school.

Exposures to $\mathrm{NO}_{2}$ were measured by passive sampling with Palmes diffusion tubes. Each child was asked to wear diffusion tubes for the same three separate seven day periods between January and March 1994. Two of the study weeks were during the school term (which allowed the repeatability of the measurements to be examined), and the third covered the half term holiday. Instructions on how to wear the tubes were provided orally and in a simple booklet, and included advice on how to avoid getting the tubes wet or damaged. The tubes were attached to necklaces, and taken off and placed in the bedroom at night.

In the same weeks, the subjects were asked to place two further tubes in their homes, one in the kitchen and one in the living room. Specially designed holders were provided to position the tubes, and the booklet gave instructions on their siting (about $1.5 \mathrm{~m}$ above the ground, and as far as possible from 
draughts and potential sources of $\mathrm{NO}_{2}$ such as cookers or heaters). Also, tubes were placed in the playground and classroom at each school.

Care was taken to ensure that all tubes were uncapped and recapped at the correct times. At the end of each measurement period, the tubes were sent for analysis to the Department of Health and Consumer Affairs, Rotherham, United Kingdom, a member of the Warren Spring laboratory quality control programme.

Statistical analysis was performed with the SPSS statistical package. ${ }^{10}$ The $\mathrm{NO}_{2}$ measurements were positively skewed and a logarithmic transformation was used to normalise them and to stabilise the variance. When data for each week were analysed separately, standard multiple linear regression methods were used. When data for more than one week were considered together, geometric means of the results for the available weeks were calculated, and weighted regression methods were used to give greater weight to the data for children with more measurements. In calculating correlation coefficients a similar weighted method was used. ${ }^{11}$

\section{Results}

Of the 50 children who were invited to participate in the study, 46 provided at least one personal $\mathrm{NO}_{2}$ sample (44 in week 1, 30 in week 2 , and 23 in week 3 ). The geometric mean (range) of the 97 personal $\mathrm{NO}_{2}$ measurements were $36(11-257) \mu \mathrm{g} / \mathrm{m}^{3}$. Two children had personal exposures in excess of $100 \mu \mathrm{g} / \mathrm{m}^{3}$ during at least one of the weeks studied, including one child with exceptionally high concentrations in both week 1 and week $2\left(204 \mu \mathrm{g} / \mathrm{m}^{3}\right.$ and $257 \mu \mathrm{g} / \mathrm{m}^{3}$ ).

Figure 1 shows personal $\mathrm{NO}_{2}$ exposures during weeks 1 and 2 in the children who provided samples for both of these periods. In most children, the concentration in week 2 was lower than that in week 1 , but the difference was small in comparison with the variability of exposures between children. In contrast, concentrations recorded in the school playgrounds were higher in the second

Figure 1 Comparison of personal $\mathrm{NO}_{2}$ exposure measurements in week 1 with those made in week 2 (both school weeks).

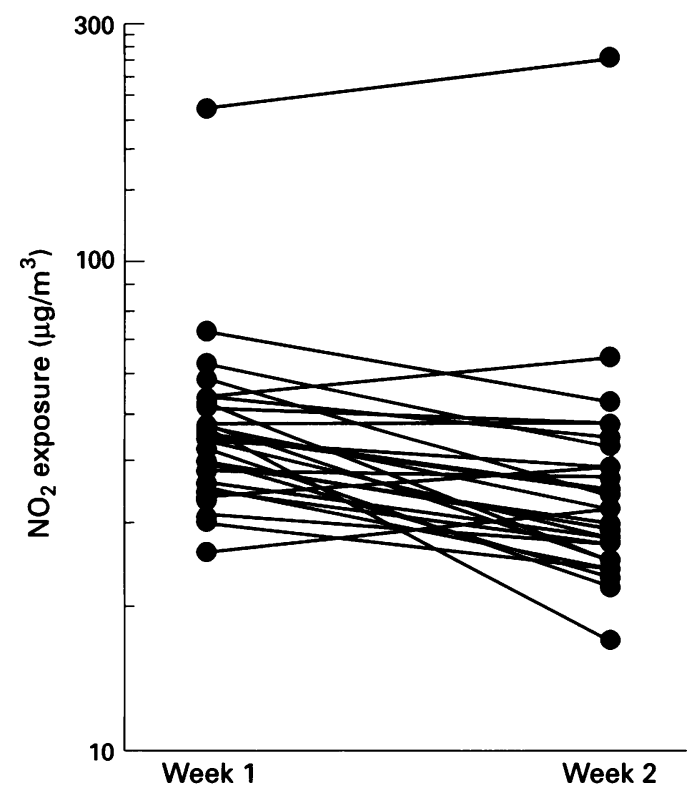

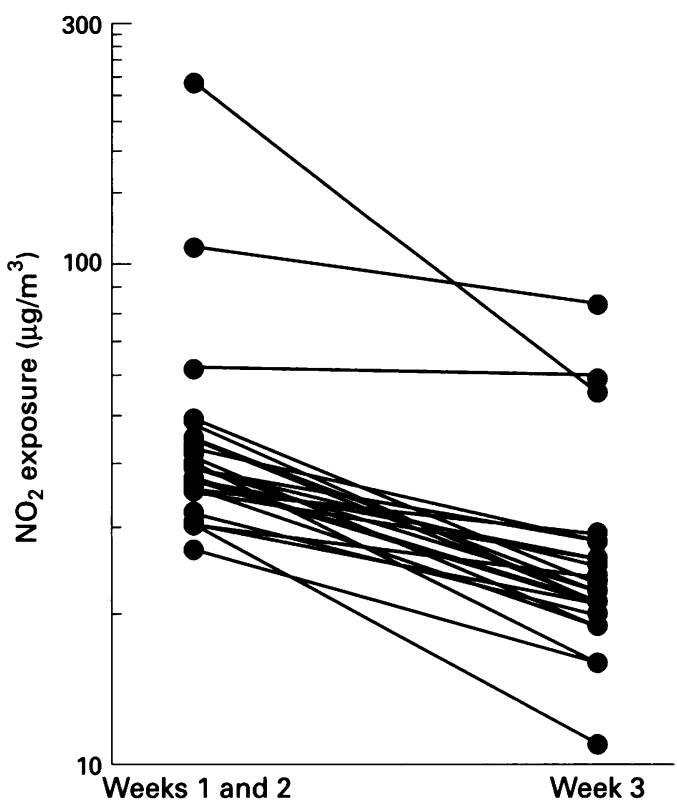

Figure 2 Comparison of personal $\mathrm{NO}_{2}$ exposure measurements in weeks 1 and 2 (at school) with those in week 3 (holiday week). For children monitored in both weeks 1 and 2, the geometric mean of the $\mathrm{NO}_{2}$ measurement is used, otherwise the only available measurement is used.

week ( 63 and $77 \mu \mathrm{g} / \mathrm{m}^{3}$ ) than in the first (57 and $\left.54 \mu \mathrm{g} / \mathrm{m}^{3}\right)$. Classroom measurements in one school were lower in week $2\left(16 \mu \mathrm{g} / \mathrm{m}^{3}\right)$ than week $1\left(27 \mu \mathrm{g} / \mathrm{m}^{3}\right)$, whereas at the other school they were virtually unchanged (23 $\mu \mathrm{g} / \mathrm{m}^{3}$ in week 1 , and $24 \mu \mathrm{g} / \mathrm{m}^{3}$ in week 2 ).

Figure 2 compares personal $\mathrm{NO}_{2}$ measurements during week 3 (half term holiday week) with those recorded in the same children in weeks 1 and 2 . In all but one child, the concentration was lower in week 3.

Forty four children provided $\mathrm{NO}_{2}$ samples from their kitchen and living room for at least one week of the study ( 40 in week 1,33 in week 2 , and 22 in week 3 ). Concentrations were again distributed in a log normal fashion with a geometric mean (range) of 52 (14-447) $\mu \mathrm{g} / \mathrm{m}^{3}$ for kitchens and $40(14-315) \mu \mathrm{g} / \mathrm{m}^{3}$ for living rooms. There was little variation in the mean concentrations from week to week. Eight houses had at least one kitchen concentration above $100 \mu \mathrm{g} / \mathrm{m}^{3}$, and four had living room concentrations above this threshold. These included the house of the child with unusually high personal exposures (kitchen concentration $=447 \mu \mathrm{g} / \mathrm{m}^{3}$ in week 1,168 $\mu \mathrm{g} / \mathrm{m}^{3}$ in week 2 , and $440 \mu \mathrm{g} / \mathrm{m}^{3}$ in week 3 ; living room concentrations $=281 \mu \mathrm{g} / \mathrm{m}^{3}$ in week $1,219 \mu \mathrm{g} / \mathrm{m}^{3}$ in week 2 , and $315 \mu \mathrm{g} / \mathrm{m}^{3}$ in week $3)$. Kitchen and living room measurements in the same house were correlated (correlation coefficient after log transformation and adjustment for repeated measurements in some houses was 0.75 , and with the outlying child excluded 0.63).

Table 1 summarises the relation of personal $\mathrm{NO}_{2}$ measurements to kitchen and living room concentrations in the same week. If anything, personal measurements were more closely correlated with the measurements recorded in the kitchen than with those made in living rooms. 
Table 1 Relation of personal $\mathrm{NO}_{2}$ concentrations with those in the kitchen and living room in the same week

\begin{tabular}{|c|c|c|c|}
\hline \multirow[b]{2}{*}{ Week } & \multirow[b]{2}{*}{ Children $n$} & \multicolumn{2}{|c|}{ Correlation with personal $\mathrm{NO}_{2}$ concentrations } \\
\hline & & Kitchen $\mathrm{NO}_{2}$ & Living room $\mathrm{NO}_{2}$ \\
\hline 1 & 40 & $\begin{array}{l}0 \cdot 76^{\star \star} \\
\left(0 \cdot 65^{\star \star}\right)\end{array}$ & $\begin{array}{l}0 \cdot 64^{\star \star} \\
\left(0.43^{\star}\right)\end{array}$ \\
\hline 2 & 27 & $\begin{array}{c}0.53^{\star} \\
(0.27)\end{array}$ & $\begin{array}{l}0.61^{\star \star} \\
(0 \cdot 31)\end{array}$ \\
\hline 3 & 20 & $\begin{array}{c}0 \cdot 74^{\star \star} \\
\left(0 \cdot 68^{\star \star}\right)\end{array}$ & $\begin{array}{c}0.65^{\star} \\
\left(0.56^{\star}\right)\end{array}$ \\
\hline
\end{tabular}

$\star P<0.05 ;{ }^{\star}{ }^{\star} P<0.01$.

Correlation coefficients were derived after $\log$ transformation of all measurements. The values in parentheses were calculated after exclusion of one outlying child with exceptionally high NO exposures.

Table 2 Proportional change in $\mathrm{NO}_{2}$ associated with the presence of various risk factors as derived from regression analysis, with data from the 43 children who returned a questionnaire

\begin{tabular}{|c|c|c|c|}
\hline $\begin{array}{l}\text { Risk } \\
\text { factor }\end{array}$ & $\begin{array}{l}\text { Children } \\
\text { exposed to } \\
\text { risk factor } \\
n\end{array}$ & $\begin{array}{l}\text { Proportional } \\
\text { change in } \mathrm{NO}_{2} \\
\text { between weeks } 1 \text { and } 2 \\
(95 \% \mathrm{CI})\end{array}$ & $\begin{array}{l}\text { Proportional } \\
\text { change in } \mathrm{NO}_{2} \\
\text { between weeks } 1 \text { and } 2 \\
\text { combined and week } 3 \\
(95 \% \mathrm{CI})\end{array}$ \\
\hline $\begin{array}{l}\text { Gas fire at home } \\
\text { Gas cooker at home } \\
\text { Gas cooker with pilot light at home } \\
\text { Gas central heating at home } \\
\text { Any gas appliance at home } \\
\text { ₹ } 1 \text { smoker in household } \\
\text { Travel to school by cycle, bus, }\end{array}$ & $\begin{array}{l}13 \\
32 \\
10 \\
34 \\
40 \\
25\end{array}$ & $\begin{array}{l}1.06(0.89-1.26) \\
1.14(0.94-1.38) \\
1.27(1.06-1.51) \\
0.88(0.80-1.22) \\
1.04(0.70-1.57) \\
1.16(0.99-1.36)\end{array}$ & $\begin{array}{l}1.34(0.90-1.99) \\
1.34(0.85-2.08) \\
1.22(0.79-1.90) \\
1.14(0.67-1.92) \\
1.06(0.41-2.72) \\
1.22(0.84-1.80)\end{array}$ \\
\hline $\begin{array}{l}\text { or on foot } \\
\text { Travel all or part of journey by car }\end{array}$ & $\begin{array}{l}35 \\
12\end{array}$ & $\begin{array}{l}1.08(0.86-1.35) \\
0.83(0.70-0.99)\end{array}$ & - \\
\hline
\end{tabular}

When the measurements obtained from the outlying child were excluded from the analysis, the correlations were weaker, and in week 2 , they ceased to be significant.

Questionnaires about possible exposures to $\mathrm{NO}_{2}$ were completed by 43 children. Table 2 shows the influence of these variables on personal $\mathrm{NO}_{2}$ concentrations when they were examined in separate regression models. Results are presented for weeks 1 and 2 when the children were at school, and week 3 , when they were on holiday. Unfortunately, the child with very high $\mathrm{NO}_{2}$ exposures did not return a questionnaire. In weeks 1 and 2, personal exposure was positively associated with the presence of gas appliances in the home, at least one smoker in the household, and travel to school by cycle, bus, or foot. However, together these variables accounted for less than $30 \%$ of the variation in personal exposure, and only one association-that with a gas cooker having a pilot light-was significant at the $5 \%$ level. Also, there was a significant negative association with travelling to school by car. In week 3, the estimated influence of gas appliances in the home was larger, but because fewer children were included in the analysis, none of the associations were significant.

\section{Discussion}

In the sample of schoolchildren studied, personal exposures to $\mathrm{NO}_{2}$ averaged over a week were almost all in the range $10-80 \mu \mathrm{g} / \mathrm{m}^{3}$. The variation between children was greater than that between different time periods in the same child, although personal exposures clearly changed from week to week. Differences between children were influenced by the presence of gas appliances in the home, living with one or more smokers, and means of transport to and from school, but together these variables only explained a small part of the variation in personal exposures. Personal exposures correlated with concentrations of $\mathrm{NO}_{2}$ measured in the home, but the relation was far from exact. Despite previous findings ${ }^{9}$ there was no notable difference between either indoor or outdoor $\mathrm{NO}_{2}$ concentrations at the two schools or between the two sets of pupils' personal exposure measurements.

The technique that we used for passive monitoring of $\mathrm{NO}_{2}$ is well established and reliable. The use of passive diffusion tubes for monitoring both indoor and outdoor locations has been thoroughly investigated, ${ }^{12} 13$ and the detection limit for a one week exposure time is approximately $3 \mu \mathrm{g} / \mathrm{m}^{3}{ }^{14}$ It is possible that some health effects of $\mathrm{NO}_{2}$ result from short term peaks of exposure, and ideally exposures should be measured over shorter intervals as well as by a weekly average. ${ }^{15}$ However, techniques for continuous monitoring of short term personal exposures to $\mathrm{NO}_{2}$ are not yet available.

Although some children did not complete questionnaires and many did not provide $\mathrm{NO}_{2}$ measurements in all three weeks of the survey, the overall response to the study was good. Compliance with the protocol was encouraged by making the survey part of a school project carried out by the children, and teachers ensured that children were wearing their diffusion tubes correctly during school hours. Also, care was taken to ensure that tubes were uncapped and recapped at the correct times. Thus, we have no reason to suspect serious errors in the collection of samples.

In several homes the average weekly concentrations of $\mathrm{NO}_{2}$ in kitchens or living rooms exceeded the current European Union's guide value for outdoor concentrations of $135 \mu \mathrm{g} / \mathrm{m}^{3}$, expressed in terms of the 98 th percentile of hourly means over one year. Of these homes, all used gas, or a combination of gas and electricity, for cooking. As cooking is carried out intermittently, short term concentrations in kitchens may have been substantially higher. Studies of mothers and young children in the Netherlands ${ }^{15}$ and of adults in the United States ${ }^{16}$ have suggested that indoor concentrations of $\mathrm{NO}_{2}$ provide a good estimate of personal exposure, but this was not the case in our study. The discordance could be explained by the fact that our subjects were all children aged 9-11 years, a group who may spend more time out of the house than women and younger children, and less time in the kitchen during the preparation and cooking of meals.

As well as gas appliances in the home, factors that were associated with higher personal exposure to $\mathrm{NO}_{2}$ included the presence of one or more smokers in the household, and travel to school by means other than a car. Cigarette smoking in indoor environments is known to increase concentrations of $\mathrm{NO}_{2}$, depending upon the number of smokers, the intensity of smoking, and ventilation rates. ${ }^{17}$ The lower exposures in children who travelled to school by car may, in part, reflect a shorter journey time with less exposure to traffic fumes. 
The consistent fall in personal exposures during the half term holiday was not explained by a reduction in $\mathrm{NO}_{2}$ concentrations in the children's homes. Nor can it be attributed to unusually high exposures in school classrooms during the first two weeks of the study as classroom concentrations were lower than most personal exposures. We do not have information on the outdoor concentrations of $\mathrm{NO}_{2}$ to which the children were exposed during the holiday week, but the holiday did not coincide with any notable change in the weather, which was mild in all three weeks of sampling. We were able to establish where 19 of the 23 children studied in week 3 had spent their holiday, and only two had been away from the Southampton area for more than one day. Perhaps the reason for the lower exposures in week 3 was a reduction in exposure to traffic fumes as a result of not having to travel to and from school. Unfortunately no information on traffic density was obtained, which might have helped to explain the differences in exposure.

In contrast to other studies, ${ }^{15} 16$ indoor concentrations of $\mathrm{NO}_{2}$ and proxy markers, such as the use of gas cookers and heaters, did not seem to be sufficiently reliable indicators of personal exposure. Thus our findings support the need for direct personal monitoring to assess exposure in studies investigating the health effects of $\mathrm{NO}_{2}$ in older children. Because passive samplers can only measure longer term average exposures, other sources of information such as activity diaries, weather conditions, and traffic density may also be needed to assess possible peak exposures.

1 World Health Organisation. Air quality guidelines for Europe. WHO: Copenhagen, 1987. (European Series No 23.)
2 Melia RJW, Florey C du V, Chinn S. The relation between respiratory illness in primary school children and the use of gas for cooking. Results from a national survey. Int $\mathcal{F}$ Epidemiol 1979;8:333-8.

3 Speizer FE, Ferris B Jr, Bishop YMM, Spengler J. Respiratory disease rates and pulmonary function in children associated with $\mathrm{NO}_{2}$ exposure. Am Rev Respir Dis 1980; 121:3-10.

4 Brunekreef B, Houthuijs D, Dijkistra L, Boleij JSM. Indoor nitrogen dioxide exposure and children's pulmonary function. F Air Waste Manage Assoc 1990;40:1252-6.

5 Dijkistra L, Houthuijs D, Brunekreef B, Akkerman I, Bolei JSM. Respiratory health effects of the indoor environment on a population of Dutch children. Am Rev Respir Dis 1990;142:1172-8.

6 Goings S, Kulle T, Bascom R, Sauder LR, Green DJ, Hebel JR, Clements ML. Effect of nitrogen dioxide exposure on susceptibility to influenza A virus infection in healthy adults. Am Rev Respir Dis 1989;139:1075-81.

7 Institute for Environment and Health. IEH Report on air pollution and respiratory disease; UK research priorities 1994. pollution and respiratory disease; UK research priorities 1994.

8 Commission of the European Communities. Report series on air pollution epidemiology: health effect assessment. Brussels: Commission of the European Communities, 1991 (Report No 2.)

9 Brown C, Sillence A. Survey of $\mathrm{NO}_{2}$ levels in Southampton 1992-3. Southampton: University of Southampton 1993.

10 SPSS. SPSS base manual SPSS PC+V2·0. Chicago, SSPS, 1988.

11 Bland JM, Altman DG. Calculating correlation coefficients with repeated observations: part 2-correlation between with repeated observations:
subjects. $B M \mathcal{F}$ 1995;310:633.

12 Apling AJ, Stevenson KJ, Goldstein BD, Melia RJ, Atkins DHF. Air pollution in homes 2: validation of diffusion tube measurements. Stevenage: Warren Spring Laboratory, 1979. (Report LR 311.)

13 Atkins DHF, Sandalls J, Law DV, Hough AM, Stevenson $\mathrm{KJ}$. The measurement of nitrogen dioxide in the outdoor environment using passive diffusion tube samplers. Harwell: HMSO, AERE 1986. (AERE R 12133.)

14 Commission of the European Communities. Report series on air pollution epidemiology: exposure assessment. Brussels:
Commission of the European Communities, 1991. (Report No 1.)

15 Noy D, Brunekreef B, Boleij JSM, Houthuijs D, De Konig R. Assessment of respiratory exposure to nitrogen dioxide in epidemiology studies. Atmospheric Environmen 1990;248:2903-9.

16 Leaderer BP, Zagraniski RT, Berwick M, Stolwijk JAJ. Assessment of exposure to indoor air contaminants from combustion sources; methodology and application. $A m \mathfrak{F}$ Epidemiol 1986;124:275-89.

17 Samet JM, Marbury MC, Spengler JD. Health effects and sources of indoor air pollution. Part 1. Am Rev Respir Dis 1987;136:1486-508.

\section{Rejected manuscripts}

From February 1994, authors whose submitted articles are rejected will be advised of the decision and one copy of the article, together with any reviewers' comments, will be returned to them. The fournal will destroy remaining copies of the article but correspondence and reviewers' comments will be kept. 